\title{
Analisis Gerak Teknik Lempar Lembing Gaya Silang (Cross Step) Pada Atlet Lempar Lembing Putri UAC (Unimed Athletic Club)
}

\author{
Mesrawati Telaumbanua, David Siahaan \\ Fakultas Ilmu Keolahragaan, Universitas Negeri Medan \\ Mesrapurry@gmail.com,davsfik@gmail.com
}

\begin{abstract}
Abstrak: Tujuan penelitian ini untuk menganalisis dan mengetahui gerak lempar lembing gaya silang (Cross Step) Pada Atlet Lempar Lembing Putri UAC (Unimed Athletic Club) Tahun 2019. Indikator dalam penelitian ini adalah untuk mengetahui kemampuan teknik lempar lembing atlet lempar lembing putri UAC yang terdiri dari langkah awalan, cross step, meluncur, melempar, dan pemulihan. Metode penelitian yang digunakan adalah metode deskriptif kualitatif, yang menjelaskan keadaan yang sebenarnya dan cenderung memberikan hasil data daripada teori. Untuk menganalisis data, setiap atlet akan melakukan teknik lempar lembing dan peneliti akan mengaplikasikannya dengan menggunakan aplikasi dartfish, penilaian dari beberapa ahli kemudian membandingkan dengan atlet nasional. Hasil penelitian berdasarkan analisis rangkaian gerak pada subjek penelitian menghasilkan lemparan terjauh terjadi pada lemparan atlet pembanding Sri Astuti dengan jarak 41,90 meter dengan jarak rerata setiap langkah 1,08. Sementara jarak terjauh berikutnya adalah Lastiar Ayu Natalia dengan jarak 36 meter dan jarak rerata setiap langkah 1,32 meter. Subjek penelitian yang terakhir Loister Eunike Hutasoit hasil lemparan sejauh 16,30 meter, hasil penelitian menunjukan bahwa masih perlu drill dan latihan yang intensif kepada atlet untuk meningkatkan hasil lemparannya lebih jauh. Dapat disimpulkan bahwa menganalisis gerak lempar lembing ini sangat diperlukan dalam dunia olahraga untuk memperoleh informasi tentang rangkaian gerak lempar lembing, dapat mengetahui kebenaran gerak dengan hasil yang akurat serta jadi bahan masukan buat para pelatih dalam mengevaluasi kemampuan gerak atlet.
\end{abstract}

Kata Kunci: Lempar lembing, Cross step

\section{The Analysis of Cross Step Javelin Throw Technique in Female UAC (Unimed Athletic Club) Javelin Athletes}

\begin{abstract}
The purpose of this study to analyze and determine the motion javelin style cross (Cross Step) In the Women's Javelin Throw Athletes UAC (Unimed Athletic Club) Year 2019. The indicators in this study were to determine the ability of the technique javelin female athlete UAC comprising the steps prefix, cross step, slide, throw, and recovery. The research uses the qualitative description method, which describes the actual situation and tends to give the results of the data rather than theory. To analyze the data, each athlete will perform the javelin technique and researchers will apply it using dartfish Software and by expert athletics javelin then compared with the national athletes. The results based on the analysis of the dartfish range of motion analysis research on the subject produces the farthest throw occurred in comparison to Sri Astuti athletes throw with a distance of 41.90 meters with an average distance of each step of 1.08. While the next farthest distance is the distance Lastiar Ayu Natalia with a mean distance of 36 meters and 1.32 meters each step, and the latest research subject Loister Eunice Hutasoit throw results as far as 16.30 meters, the research results show that still need to drill and intensive training to throw athletes to improve results even further. It can be concluded that analyze the motion of the javelin is very necessary in the world of sports to obtain information about the range of motion of the javelin and can know the truth movement with accurate results and so the input material for trainers to evaluate the ability of the athlete motion.
\end{abstract}

Keywords: Javelin throw, Cross step 


\section{PENDAHULUAN}

Lempar lembing adalah olahraga yang dilakukan dengan cara melempar lembing dengan satu tangan sekuat tenaga bertujuan untuk mencapai jarak sejauh-jauhnya, sesuai dengan peraturan yang berlaku (Syarifuddin, 1992:159). Lembing atau tongkat terbuat dari metal ringan (dahulu menggunakan kayu) yang berujung runcing atau disebut mata lembing yang terbuat dari logam. Serta lilitan tali pegangan yang terletak dan dililitkan dipusat gravitasi lembing. Dalam olahraga Lempar lembing, ada dua teknik gaya dalam memulai awalan hingga melakukan lemparan yaitu: 1) Gaya Langkah Jingkat (Hop Step) dan 2) Gaya Langkah Silang (Cross Step).

Lembing yang digunakan dalam pertandingan lempar lembing memiliki standart Internasional yang lembing untuk atlet putra memiliki panjang 2,60-2,70 meter dengan berat 800 gram, sedangkan lembing untuk atlet putri berukuran penjang 2,20-2,230 meter dengan berat 600 gram. Dalam pertandingan berskala internasional semua lembing disediakan dan diperiksa oleh panitia penyelenggara, dalam pertandingan atlet lempar lembing hanya bole menggunakan awalan hingga melempar pada tempat yang disediakan, melempar melebihi batas yang ditentukan merupakan lemparan yang tidak sah, pendaratan lembing dinyatakan sah apabila bagian lembing yang jatuh terlebih dahulu merupakan mata lembing pada area yang disediakan dengan posisi menancap tanah. Semua atlet akan bertanding untuk memperoleh jarak terjauh yang telah terlempar dan masing-masing atlet hanya memiliki satu kali kesempatan untuk melempar lembing.

Unimed Athletic Club atau UAC merupakan salah salah klub olahraga yang ada di kampus Universitas Negeri Medan, dalam klub ini terdiri dari beberapa cabang olahraga yaitu olahraga jalan cepat, cabang olahraga atletik berlari, cabang olahraga atletik melempar, dan cabang olahraga atletik melompat. Adapun lokasi atlet berlatih secara rutin di stadion Unimed dengan program latihan yang ditentukan oleh setiap pelatih masing-masing cabang olahraga, para atlet UAC telah mengikuti berbagai event kejuaraan atletik baik tingkat kabupaten, provinsi, nasional, bahkan internasional.

Analisis gerakan dalam olahraga sangat perlu dilakukan baik oleh pelatih maupun ahli biomekanik untuk memperbaiki kesalahan gerakanan. Pada proses pembentukan teknik lempar lembing yang baik dan benar tidak hanya mengandalkan pengamatan secara sepintas yang tidak dapat ditangkap oleh mata kita, sehingga diperlukan dukungan ilmu pengetahuan dan teknologi agar meminimalisir berbagai kesalahan yang dapat terjadi pada saat melakukan gerakan lempar lembing.

Salah satu teknologi yang digunakan untuk menganalisis gerakan dalam bidang olahraga yaitu progam aplikasi Dartfish Sedangkan ilmu pengetahuan yang dapat mendukung dalam proses pembentukan dan evaluasi teknik yaitu analisis gerak yang menggunakan prinsip-prinsip ilmu biomekanika. Semua gerakan manusia tidak lepas dari prinsip-prinsip fisika, dan pelatih juga perlu memperhatikan faktor-faktor mekanika yang mempengaruhi penampilan atlet. Salah satu fungsi dari penguasaan prinsip-prinsip mekanika oleh para pelatih adalah dapat mengembangkan keterampilan atlet dan dalam merancang teknik-teknik latihan yang cocok dan efisien bagi atlet (Pate, 1993:177).

Menurut pandangan biomekanika, lempar lembing termasuk jenis keterampilan yang diklasifikasikan dalam melontarkan objek untuk mencapai jarak horizontal maksimal. Untuk menggerakkan sebuah benda makin menjauhi pusat bumi maka makin besar juga tenaga yang harus dikerahkan. Lintasan lembing dalam lempar lembing dalam konsep biomekanika bisa disebut sebagai proyektil dalam olahraga, atau bisa juga disebut sebagai gerak parabola.

Sehubungan pelatih dan atlet kurang memperhatikan gerak yang dilakukan dalam melakukan lemparan pada lempar lembing, serta sampel atau subjek yaitu atlet putri UAC (Unimed Athletic Club) maka dalam penelitian ini peneliti melakukan penelitian terkhusus untuk menganalisis gerak lempar lembing gaya silang (Cross Step) pada atlet putri UAC.

\section{METODE}

Metode yang digunakan penelitian ini adalah metode deskriptif kualitatif. Pada penelitian ini yang dianalisis yaitu teknik gerak atlet dimulai dari: (1) start, (2) cross step (langkah silang), (3) menarik lembing/meluncur, dan (4) pemulihan. Adapun peta konsep penelitian sebagai berikut: 


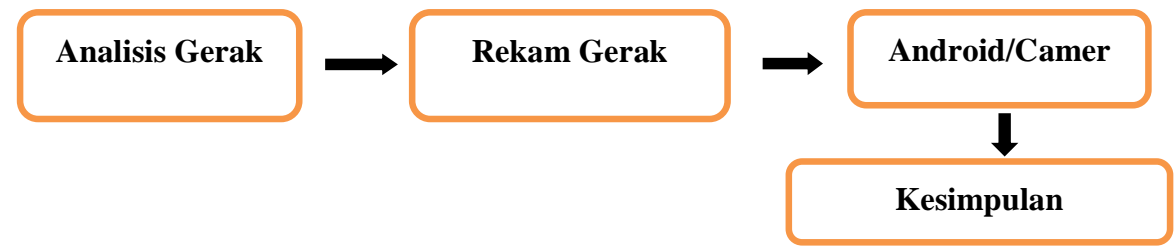

Gambar 1. Peta Konsep Penelitian

Subjek dalam penelitian ini adalah 2 orang atlet lempar lembing putri UAC dan seorang atlet sebagai data pembanding. Peneliti menggunakan purposive sampling untuk pemilihan subjek pada penelitian ini, dengan mengkhususkan pada subjek yang sesuai dengan purpose atau tujuan dalam penelitian ini.

Untuk mengumpulkan data, tehnik yang digunakan adalah penelitian yang berjenis deskriptif kualitatif. Dari hasil yang di dapat, peneliti membandingkan sampel yaitu atlet putri UAC dengan pembanding yaitu atlet lempar lembing putri yang sudah memiliki prestasi ditingkat nasional. Penganalisian data dibantu dengan aplikasi Dartfish bersumber dari video gerak lempar lembing atlet untuk dianalisis gerakannya saat atlet melakukan lempar lembing. Peneliti menganalisis teknik gerak lempar lembing pada bagian kinematika linear, kinematika anguler dan langkah atlet dengan menggunakan rumus sebagai berikut:

\section{HASIL DAN PEMBAHASAN}

Untuk melakukan penelitian analisis gerak lempar lembing gaya silang (Cross Step) pada atlet lempar lembing UAC maka tahap pertama yang dilakukan peneliti yaitu memulai dengan menghitung jumlah langkah ketiga atlet sehingga diperoleh hasil langkah ke tiga atlet terlihat pada tabel dibawah ini:

Tabel 1. Jumlah Langkah Atlet Dalam Melakukan Lemparan Lembing

\begin{tabular}{llllll}
\hline No & Nama Atlet & Awalan & Menarik Lembing & Meluncur & Pemulihan \\
& & & & & \\
\hline 1 & Sri Astuti & Langkah 1-10 & Langkah 11-12 & Langkah 13 & Langkah 14 \\
\hline 2 & Lastiar Ayu Natalia & Langkah 1-12 & Langkah 13-17 & Langkah 18 & Langkah 19 \\
\hline 3 & Loister Eunike Hutasoit & Langkah 1-4 & Langkah 5-12 & Langkah 13 & Langkah 14
\end{tabular}

Jika dilihat pada grafik perpindahan sudut atau posisi sudut yang dilakukan Sri Astuti lebih besar dibandingkan dengan Lastiar dan Loister, demikian juga pada panjang lintasan. Sedangkan pada kecepatan sudut Loister lebih cepat jika dibandingkan dengan Sri Astuti dan Lastiar hingga pada kecepatan linear dari lembing tersebut.

\section{Kinematia Angular Shoulder Pada Saat Melempar Lembing}

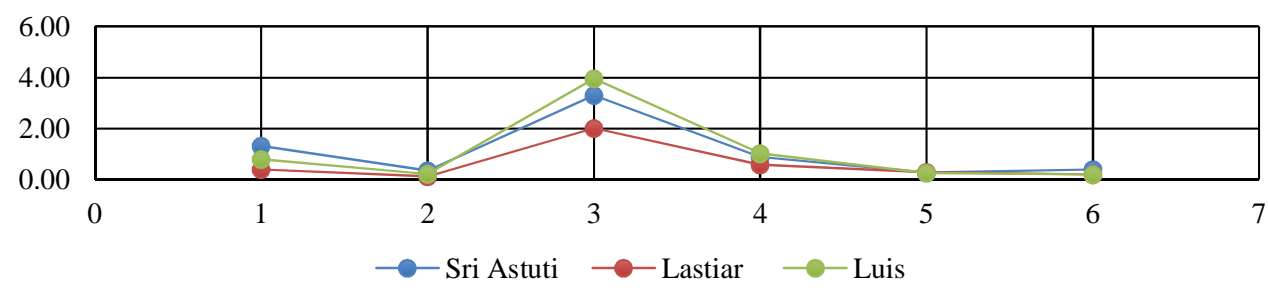

Gambar 2. Kinematika Angular Shoulder Pada Saat Melempar 
Jika dilihat pada grafik perpindahan sudut atau posisi sudut hampir sama pada ketiga atlet tetapi pada kecepatan sudut elbow Sri Astuti lebih besar melakukan gerak angular yang diikuti dengan Lastiar dan Loister. Pada kecepatan liner lembing Sri Astuti lebih cepat dibanding dengan kedua atlet tersebut. Sehingga dengan demikian dapat disimpulkan bahwa dalam melakukan lemparan gerakan pada elbow dan wriste yang perlu dipercepat sehingga dapat menghasilkan lemparan yang lebih jauh.

\section{Kinematia Angular Elbow Pada Saat Melempar Lembing}

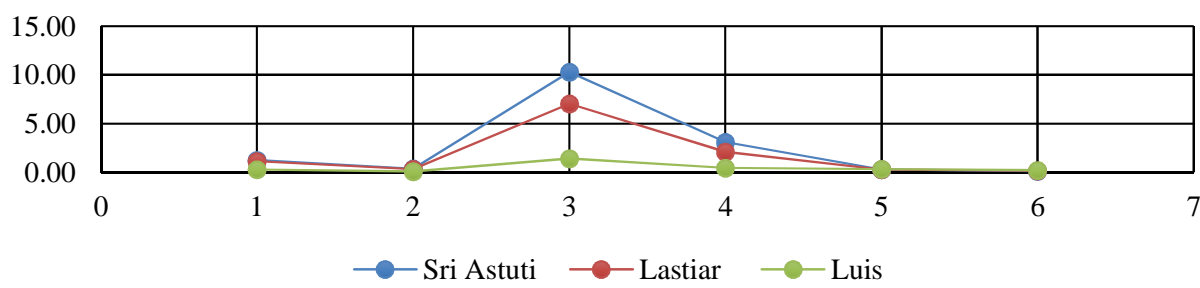

Gambar 3. Kinematika Angular Elbow Pada Saat Melempar

Wriste menjadi sendi terakhir yang bergerak pada saat melakukan lemparan pada lembing. Jika dilihat pada grafik perpindahan sudut atau posisi sudut yang dilakukan Sri Astuti lebih besar dibandingkan dengan Lastiar dan Loister, demikian juga pada panjang lintasan, kecepatan sudut dan kecepatan linear pada sendi wriste. Hal tersebut dapat menciptakan kecepatan lembing yang lebih besar sehingga jarak tempuh lembing tersebut akan semakin jauh.

\section{Kinematia Angular Wriste Pada Saat Melempar Lembing}

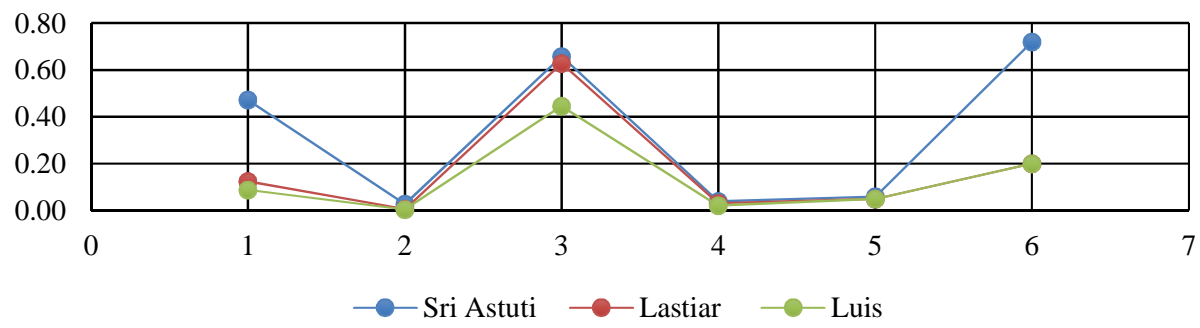

Gambar 4. Kinematika Angular Wriste Pada Saat Melempar

Dari data yang telah dijabarkan tentang hasil penelitian analisis gerak lempar lembing gaya silang (Cross Step) pada atlet putri UAC maka hasil lempar lembing yang dilakukan oleh atlet binaan UAC dapat dilihat pada tabel dibawah ini:

Tabel 2. Hasil Lemparan Lembing Atlet Binaan UAC

\begin{tabular}{clcc}
\hline No & \multicolumn{1}{c}{ Nama Atlet } & Klub Binaan & Hasil Lemparan \\
\hline 1 & Sri Astuti & UAC & 41,90 \\
\hline 2 & Lastiar Ayu Natalia & UAC & 36 \\
\hline 3 & Loister Eunike Hutasoit & UAC & 16,30 \\
\hline
\end{tabular}

Dimana yang terjauh adalah Sri Astuti dengan jarak 41,90 meter dimana atlet ini telah banyak mengikuti pertandingan lempar lembing baik di tingkat daerah maupun nasional. Atlet ini merupakan 
atlet senior dan sudah berlatih di Unimed sejak lama. Jarak terjauh berikutnya adalah Lastiar Ayu Natalia dengan jarak 36 meter. Masih perlu dilakukan pembinaan yang intensif pada atlet ini untuk meningkatkan kemampuan lempar lembingnya agar dapat berprestasi ditingkat nasional. Sedangkan subjek penelitian yang terakhir adalah Loister Eunike Hutasoit yang mana atlet ini hanya dapat melakukan lemparan pada lembing sejauh 16,30 meter. Masih perlu drill dan latihan yang intensif kepada atlet ini untuk meningkatkan hasil lemparannya lebih jauh.

Dari hasil penelitian yang diperoleh maka terlihat bahwa tahapan-tahapan dalam melakukan lempar lembing perlu untuk diperhatikan kebenaran geraknya mulai dari langkah dan Gerak linear yaitu (1) Tahap awalan, (2) Tahap menarik lembing, langkah menyilang (Cross Step), (3) Tahap langkah meluncur/melempar lembing, anguler dan langkah pada teknik lempar lembing yang dilakukan oleh atlet lempar lembing putri UAC.

Seperti terlihat pada hasil langkah ketiga atlet yaitu: (1) Sri Astuti dengan total langkah sebanyak 14 langkah yaitu awalan 1-10 langkah, menarik lembing 11-12 langkah, meluncur langkah ke 13, dan pemulihan langkah ke 14; (2) Lastiar Ayu Natalia dengan total langkah sebanyak 19 langkah yaitu awalan 1-12 langkah, menarik lembing 13-17 langkah, meluncur langkah ke 18, dan pemulihan langkah ke 19; dan (3) Loister dengan total langkah sebanyak 14 langkah yaitu awalan 1-5 langkah, menarik lembing 5-12 langkah, meluncur langkah ke 13, dan pemulihan langkah ke 14.

Pada hasil langkah tahap awalan, dan Cross Step, pada tahap ini terdapat perbedaan ketiga atlet tersebut kita dapat mengetahui perbandingan langkah ketiga atlet serta kinematika linear, sehingga dapat melakukan perbandingan antara subjek dengan pembanding khusus untuk langkah dan kinematika linear.

Pada atlet pembanding langkah awalan yang dia lakukan ada 10 langkah, dan pada langkah menarik lembing hanya 2 langkah saja yaitu pada langkah ke 12-13, sedangkan atlet Lastiar pada tahap awalan langkah awalan yang dia lakukan 12 langkah, dan tahap menarik lembing 4 langkah yaitu dari langkah 13-17, kemudian atlet yang ke tiga yaitu Lois dengan langkah awalan hanya 5 langkah, dan langkah menarik lembing yaitu sebanyak 12 langkah. Peneliti mulai menghitung langkah pada saat atlet telah berada digaris lintasan lari, dari langkah pertama kaki kanan melangkahkan kaki ke depan dan kaki kiri mendarat mulai dihitung satu langkah dan begitu mengitung langkah seterusnya dan disaat yang bersamaan ketika atlet telah melangkahkan kaki kanan, peneliti mulai menghitung waktu kecepatan gerak langkah hingga atlet melakukakan lemparan yaitu ketika lembing lepas dari genggaman tangan maka waktu diberhentikan jadi, begitu cara peneliti mengambil waktu setiap atlet khusus pada tahap langkah awalan sampai melempar lembing.

Dari tahap terlihat bahwa langkah atlet pembanding Sri, pada langkah awalan ada sepuluh langkah, sedangkan lastiar sebanyak 12 langkah. 10-14 langkah, jadi dalam tahap ini terlihat dari antara ketiga talet yang jauh berbeda jumlah langkah awalannya yaitu pada atlet Lois yang melakukan tahap awalan dengan langkah yang hanya 5 langkah saja. Terlihat juga pada tahap menarik lembing yang mana atlet pembanding pada tahap menarik lembing ada 2 langkah, lastiar dengan 4 langkah, sementara lois jauh berbeda lagi langkahnya dengan ke 2 atlet pada tahap menarik lembing langkah lois menarik lembing sebanyak 7 langkah. Jadi terlihat pada tahap langkah bahwa Lois, perlu untuk mengevaluasi serta memperhatikan kebenaran gerak khusus pada tahap langkah awalan dan langkah menarik lembing.

Hasil analisis kinematika linear pada tahap awalan yaitu keseluruhan jarak pada tahapan langkah awalan. Pada tahap ini, menghitung gerak linear dimana masing-masing atlet diambil kecepatan gerak linear mulai dari tahap awalan, menarik lembing, dan melempar, yaitu sehingga didapatkan waktu jarak tempuh.

Lari awalan disini dimaksud sepanjang 5-8 langkah sesuai dengan kemampuan dalam lari sprint, seperti suatu lari percepatan dan harus dalam satu garis lurus. Pada tahap ini masih tetap berlaku hukum newton I dan III. Lembing masih dibawah dalam posisi setinggi kepala dengan mata lembing tetap menunjuk sedikit ke atas. Punggung tangan menghadap kearah luar (lateral). Selama lari lengan yang membawa lembing bergerak hanya sedikit, sedangkan lengan yang lain bergerak sesuai dengan irama lari.

Pada teknik gaya silang (Cross Step) akan tampak pada saat atlet sampai pada 2-3 langkah terakhir sebelum melempar. Dimana silangan kaki dihasilkan dari putaran badan dimulai pada saat 
hendak melempar. Karena badan dimulai berputar dari arah kanan ke arah kiri. Demikian juga pada posisi kaki sehingga tampak menyilang. Gaya ini barsanding dengan memegang lembing gaya Amerika yang cenderung mengarahkan ujung lembing ke atas dengan sudut 45 derajat. Sehingga diperoleh kecepatan membawa lembing ketiga atlet. Dari ketiga atlet tersebut yang paling cepat membawa lembing pada tahap awalan adalah Sri Astuti.

Pada tahap ini dari hasil pengambilan waktu kecepatan gerak kinematika linear disarankan kepada kedua atlet yang menjadi subjek penelitian yaitu Lois dan Lastiar tersebut agak menambah kecepatan membawa lembing pada tahap awalan karena mempengaruhi hasil lemparan lembing itu sendiri.

Hasil analisis kinematika Linier Pada Tahap Menarik Lembing Langkah Menyilang (cross step) atau langkah menyilang akan tampak pada saat atlet sampai pada 2-3 langkah terakhir sebelum melempar. Silangan kaki dihasilkan dari putaran badan sejak hendak melempar hingga mulai melempar. Karena badan berputar. Karena badan berputar dari arah kanan ke kiri, demikian pula posisi kaki sehingga tampak menyilang awalan ini biasanya bersanding dengan gaya memegang lembing Amerika yang cenderung mengarahkan ujung tombak ke atas dengan sudut 45 derajat. Silangan kaki dan badan yang bersamaan dengan lengan yang melempar akan menghasilkan daya lempar yang kuat dengan arah yang lebih cenderung menyamping.

Gaya silang atau Cross Step berbeda dengan gaya Hop Step. Pada gaya silang atau Cross Step ini tubuh atlet tidak akan jatuh ke depan seusai melemparkan lembing. Kalaupun tubuh jatuh, maka tubuh tersebut akan jatuh kesamping mengikuti arah putaran tubuh dan silangan kaki.

Pada tahapan ini yang di analisis yaitu keseluruhan jarak pada tahapan langkah menarik lembing. Ketika atlet melakukan langkah pertama langkah Cross Step yaitu kaki kanan melangkah maka pengambilan waktu dimulai dan hingga kaki kiri mendarat sampai atlet melepas lembing dan saat itu waktu diberhentikan. Dan pada tahap ini peneliti juga mengukur jarak antara kaki kanan dan kaki kiri. Hasil lemparan menunjukan bahwa Sri Astuti dapat melakukan lemparan sejauh 41,90 meter, sedangkan Lois 16,30 meter dan Lastiar 36 meter disarankan kepada kedua atlet tersebut agak menambah kecepatan membawa lembing pada tahap awalan karena mempengaruhi hasil lemparan lembing itu sendiri.

Hasil gerak linier pada tahap meluncur/melempar lembing akan dipengaruhi power karena semakin besar power kita dalam melempar benda maka akan semakin besar pula kecepatan benda tersebut. Saat atlet lempar lembing melempar lembing maka gaya dari atlet tersebut akan menyebabkan lembing tersebut bergerak semakin cepat tergantung pada besar gaya yang diberikan ketika hendak melempar lembing, melemparkan benda, maka moment gaya juga harus kita perbesar sebab, semakin besar moment gaya maka gaya yang dihasilkan juga akan semakin besar sehingga menghasilkan lemparan yang jauh, ketika akan melepas lembing akan terjadi percepatan saat itu.

Pada tahapaan ini yang di analisis yaitu keseluruhan jarak pada tahapan gerak melempar lembing. Pada tahapan ini peneliti juga perlu menghitung jarak antar kaki kiri dan kaki kanan, dan menghitung waktu dari langkah atlet yaitu ketika tangan kanan atlet lurus kebelangkan maka peneliti mulai menghitung waktu hingga lembing lepas dari tangan atlet. Dari ketiga atlet tersebut yang paling lambat melakukan gerakan linier pada kaki pada saat melakukan lemparan pada lembing adalah Sri Astuti dimana pada tahap ini langkah diperlambat dengan tujuan agar langkah tetap berfokus pada tahap meluncur. Namun pada bagian lengan ketika melempar untuk dipercepat.

Disarankan kepada kedua atlet tersebut agak tidak buru-buru melakukan gerakan pada saat melakukan lemparan lembing atau meluncur. Pada tahap ini fokus atlet pada gerakan melakukan lemparan pada lembing, pemain perlu meningkatkan kecepatan pada lengan sedangkan kaki menjaga keseimbangan.

Gerak kinematika angular pada shoulder dimana menganalisisnya dimulai dari awalan melakukan lemparan hingga akhir melepas lembing. Menganalisis kinematika anguler ini dibantu dengan aplikasi darthfish untuk mengitung sudut dari awalan sampai release atau berakhirnya lemparan. Menganalisis gerak kinematika anguler pada lempar lembing shingga kita dapat membandingkan sudut antara ketiga atlet baik itu pada anguler shoulder, elbow dan release juga kita dapat mengambil waktu atlet berapa lama waktu yang digunakan ketika melakukan gerakan anguler dalam melempar lembing mulai dari awalan. Gerak rotasi yang paling sering terlihat adalah di sekitar 
sendi bahu, lengan bawah, sekitar sendi siku tangan dan sekitar sendi pergelangan tangan. Sendi panggul beraksi sebagai poros bagi tungkai, sendi lutut untuk tungkai bawah, dan sendi pergelangan kaki untuk kaki. Gerakan tergantung pada gerak rotasi dari tiap segmen (yaitu kaki, tulang kering, dan paha) anggota tubuh atlet ketika bergerak pada sendinya. Shoulder menjadi tumpuan pada lengan untuk melakukan tolakan.

Jika dilihat pada grafik perpindahan sudut atau posisi sudut yang dilakukan sri astuti lebih besar dibandingkan dengan Lastiar dan Loister, demikian juga pada panjang lintasan. Sedangkan pada kecepatan sudut Loister lebih cepat jika dibandingkan dengan Sri Astuti dan Lastiar hingga pada kecepatan linear dari lembing tersebut. Jika dilihat pada grafik perpindahan sudut atau posisi sudut yang dilakukan Sri Astuti lebih besar dibandingkan dengan Lastiar dan Loister, demikian juga pada panjang lintasan. Sedangkan pada kecepatan sudut Loister lebih cepat jika dibandingkan dengan Sri Astuti dan Lastiar hingga pada kecepatan linear dari lembing tersebut.

Gerak sendi elbow pengambilan kecepatan waktu pada tahap ini dimulai ketika tangan ditekuk hingga tangan diluruskan atau pada saat pada saat melakukan lemparan, seperti pada saat melakukan lemparan membutuhkan waktu. Elbow menjadi tumpuan kedua yang terakhir pada lengan untuk melakukan lemparan pada lembing. Jika dilihat pada grafik perpindahan sudut atau posisi sudut hampir sama pada ketiga atlet tetapi pada kecepatan sudut elbow Sri Astuti lebih besar melakukan gerak angular yang diikuti dengan Lastiar dan Loister. Pada kecepatan liner lembing Sri Astuti lebih cepat dibanding dengan kedua atlet tersebut. Sehingga dengan demikian dapat disimpulkan bahwa dalam melakukan lemparan gerakan pada elbow dan wriste yang perlu dipercepat sehingga dapat menghasilkan lemparan yang lebih jauh.

Gerak sendi wriste peneliti menganalisis dan mengambil waktu pada saat atlet memainkan pergelangan tangan hendak melepas lembing yaitu saat pergelengan tangan ditekuk kebelakang hingga lurus kedepan yaitu saat melepas lembing. Panjang lengan atau jari-jari shoulder yaitu dihitung dari panggal tangan hingga pada kepalan tangan seperti pada hasil wriste menjadi sendi terakhir yang bergerak pada saat melakukan lemparan pada lembing. Jika dilihat pada grafik perpindahan sudut atau posisi sudut yang dilakukan Sri Astuti lebih besar dibandingkan dengan Lastiar dan Loister, demikian juga pada panjang lintasan, kecepatan sudut dan kecepatan linear pada sendi wriste. Hal tersebut dapat menciptakan kecepatan lembing yang lebih besar sehingga jarak tempuh lembing tersebut akan semakin jauh.

Jadi tahapan-tahapan yang dilakukan dalam melempar lembing sangat perlu untuk diperhatikan baik setiap atlet ataupun pelatih agar diperoleh gerakan yang benar dan sempurnah sehingga atlet lempar lembing dapat memperoleh hasil lemparan yang jauh.

\section{SIMPULAN}

Subjek penelitian ini adalah dua orang atlet atletik cabang olahraga lempar lembing UAC (Unimed Athletic Club) dan subjek rangkaian analisis gerak pada subjek penelitian menghasilkan lemparan terjauh terjadi pada lemparan atlet pembanding yaitu lemparan dengan kejauhan 41,90 meter Sri Astuti dengan Total jarak tempuh yang dibutuhkan oleh Sri Astuti untuk melakukan lemparan sejauh 41,90 meter adalah 15,11 meter dengan jarak rerata setiap langkah adalah 1,08 meter.

Sedangkan Lastiar Ayu Natalia total jarak tempuh yang dibutuhkan oleh Lastiar Ayu Natalia untuk melakukan lemparan sejauh 36 meter adalah 25,09 meter dengan jarak rerata setiap langkah adalah 1,32 meter. Sementara, Loister Eunike Hutasoit dengan total jarak tempuh yang dibutuhkan untuk melakukan lemparan sejauh 16,3 meter adalah 0,86 meter.

Didalam gerak lempar lembing yang perlu dianalisis yakni gerak linear, anguler dan langkah pada teknik lempar lembing dengan tahapan-tahapan yang dilakukan pada saat melakukan analisis adalah tahapan awalan, tahapan menarik lembing dan tahapn meluncur serta yang terakhir adalah tahapan pemulihan. Tahapan tersebut perlu untuk diperhatikan baik setiap atlet ataupun pelatih agar diperoleh gerakan yang benar dan sempurnah sehingga atlet lempar lembing dapat memperoleh hasil lemparan yang jauh. 


\section{DAFTAR PUSTAKA}

Akil. (2015). Pengaruh Latihan Squat Dan Pull Over Terhadap Kemampuan Lempar Lembing Pada Siswa Smkn 1 Sul Sel. Program Pascasarjana. Jurusan Pendidikan Jasmani Dan Olahraga. Makasar: Universitas Negeri Makassar.

Ariffian, Rizky. (2017). Pengaruh Latihan Kelentukan Dan Medicine Ball Terhadap Kemampuan Lempar Lembing Gaya Cross Step Pada Siswa Putra Kelas XI SMA Negeri 1 Bandar Lampung Tahun Ajaran 2016/2017. Pendidikan Jasmani Kesehatan dan Rekreasi. Fakultas Keguruan dan Ilmu Pendidikan. Lampung: Universitas Lampung.

Arikunto. (2010). Prosedur Penelitian Suatu Pendekatan Praktek. Jakarta: PT.Bina Aksara.

Bahagia, Yoyo dkk. (2000). Atletik. Pendidikan dan Kebudayaan Direktorat Jenderal Pendidikan Dasar dan Menengah Bagian Proyek Penataran Guru SLTP setara D-III.

Gerry A. Carr. (2003). Atletik untuk sekolah. Yogyakarta: Graha Ilmu.

Giri Wiarto. (2013). Atletik. Yogyakarta: Graha Ilmu.

Hamid, A. (2000). Teori dan Praktek Atletik. Surakarta: Departemen Pendidikan dan Kebudayaan, Direktorat Jenderal Pendidikan Tinggi.

Ks, Bambang., Hakim, A.A., Kusuma, Moh. N.H. (2014). Biomekanika Olahraga. Jakarta: Asdep Tenaga Keolahragaan Deputi Bidang Peningkatan Prestasi Olahraga Kemenpora.

Kuntjoro, Bambang, F.T. (2015). Analisis Biomekanika Pada Olahraga Renang "Gaya Bebas". Phedheral. Vol. 11. No. 2.

Sidik Dikdik Zafar. (2013). Mengajar dan Melatih Atletik. Bandung: PT. Remaja Rosdakarya.

Suwadji, Ade Satria B. 2014. Analisis Gerak Lempar Lembing. (Studi pada Atlet Atletik Cabor lempar Lembing PASI Sidoarjo, Ditinjau dari aspek Biomekanika dan Kinesiologi).

Widya, Mochammad. Djumidar, A. 2004. Belajar Berlatih Gerak-Gerak Dasar Atletik Dalam Bermain. Jakarta: PT. Raja Grafindo Perindo. 